\title{
Resistance to HIV-1 infection among HIV-exposed seronegative partners in HIV-discordant couples is associated with higher frequency of CD8+ T cells expressing CD107a and b molecules
}

\author{
A Padane $^{1 *}$, M Camara ${ }^{1,2,3}$, M Seydi $^{2}$, W Jennes ${ }^{3}$, AA Diallo ${ }^{1}$, M Fall ${ }^{1}$, PA Diaw ${ }^{1}$, PS Sow ${ }^{2}$, S Mboup $^{1}$, L Kestens ${ }^{3}$, \\ T Ndiaye Dieye ${ }^{1}$
}

From Abstracts from International Symposium HIV and Emerging Infectious Diseases 2014 Marseille, France. 21-23 May 2013

\section{Background}

Some individuals remain persistently HIV-seronegative despite multiple high-risk exposures to the virus (HIVexposed seronegatives or ESN). Different mechanisms may influence host resistance to HIV infection. HIVspecific CTL has been suggested to play a role in HIV-1 protection.

\section{Methods}

Ten HIV-1 ESN in HIV-discordant couples were enrolled at the Fann University hospital, Dakar, Senegal. Thirty HIV-1 infected patients (10 HIV-1 non transmitted partners in discordant coupes and 20 HIV-1 infected partners in HIV-concordant couples) and 10 HIV-negative unexposed subjects were included as controls. Levels of CD107a and b, and CD107a/b+IFN- $\gamma+$ in CD8 + T cells sub-set were measured in fresh PBMC by flow cytometry, in the presence or absence of stimulation with SEB.

\section{Results}

HIV-negative subjects (10 ESN subjects and 10 HIV-negative controls) showed significantly lower percentages of $\mathrm{CD} 107 \mathrm{a} / \mathrm{b}+$ expression on CD8+ T-cells than did HIV-1 infected patients ( $2.9 \%$ vs. $11.6 \%, \mathrm{P}=0.016)$. Similar conclusions were reached when expression of CD107a/b+ IFN- $\gamma+$ were analyzed. Interestingly, HIV-1 ESN subjects showed higher frequency of CD8+ T cells expressing CD107a and b compared with unexposed HIV-negative controls $(11.6 \%$ vs. $1.3 \%, \mathrm{P}=0.018)$, concordant with production of intracellular IFN- $\gamma$.

\section{Conclusions}

Taken together, our data suggest that resistance to HIV-1 infection among ESN partners in HIV-discordant couples may be associated with HIV-specific CTL responses.

\section{Authors' details}

${ }^{1}$ Cheikh Anta Diop University, Laboratory of Immunology, CHU Le Dantec, Dakar, Senegal. ${ }^{2}$ Cheikh Anta Diop University, Clinic of Infectious Diseases, CHU Fann, Senegal. ${ }^{3}$ Institute of Tropical Medicine, Laboratory of Immunology, Department of Microbiology, Antwerp, Belgium.

Published: 23 May 2014

\section{doi:10.1186/1471-2334-14-S2-P67}

Cite this article as: Padane et al:: Resistance to HIV-1 infection among HIV-exposed seronegative partners in HIV-discordant couples is associated with higher frequency of CD8+ T cells expressing CD107a and b molecules. BMC Infectious Diseases 2014 14(Suppl 2):P67. 